\title{
$\mathrm{Fe}-(20,45) \mathrm{wt} \% \mathrm{Gd}$ 금속간 화합물의 기계적 특성 및 부식 거동 연구
}

\author{
강보경 $^{1} \cdot$ 백열 $^{1} \cdot$ 최용 $^{1, *} \cdot$ 문병문 $^{2}$ \\ ${ }^{1}$ 단국대학교 신소재공학과 \\ ${ }^{2}$ 한국생산기술연구원 액상 공정 및 용해 주조 연구실
}

\section{Study on the Mechanical Properties and Comosion Behaviors of Fe-(20, 45) wt\% Gd Intermetallics}

\author{
Bo Kyeong Kang ${ }^{1}$, Youl Baik ${ }^{1}$, Yong Choi ${ }^{1, *}$, and Byung Moon Moon ${ }^{2}$ \\ ${ }^{I}$ Dankook University, Department of Materials Science and Engineering, Chungnam 31116, Republic of Korea \\ ${ }^{2}$ Liquid Processing and Casting Technology R\&D Group, Korea Institute of Industrial Technology, Incheon 21999, \\ Republic of Korea
}

\begin{abstract}
Fe-(20, 45 wt\%) Gd intermetallics were vacuum arc melted as the mother alloy of a neutron shielding and absorbing material. The structure of the cast $\mathrm{Fe}-20 \mathrm{wt} \% \mathrm{Gd}$ intermetallics had primary dendrites with a short width of about $2 \mu \mathrm{m}$, which became coarse with increasing Gd content. The final compositions of the $\mathrm{Fe}-20 \mathrm{wt} \% \mathrm{Gd}$ and $\mathrm{Fe}-45 \mathrm{wt} \% \mathrm{Gd}$ intermetallics determined by Rietveld refinement were mainly $\mathrm{Fe}_{3} \mathrm{Gd}$ with 26.6 at\% $\mathrm{Fe}_{2} \mathrm{Gd}$, and $\mathrm{Fe}_{3} \mathrm{Gd}$ with various intermetallics like 13.9 at\% $\mathrm{Fe}_{2} \mathrm{Gd}, 7.3$ at\% $\mathrm{Fe}_{9} \mathrm{Gd}$ and 3.9 at $\% \mathrm{Fe}_{17} \mathrm{Gd}_{2}$, respectively. The micro-hardnesses, yield strength, ultimate compressive strength and elongation of the Fe-20 wt\% Gd intermetallics were $629 \pm 12 \mathrm{Hv}, 753 \mathrm{MPa}, 785 \mathrm{MPa}$ and $4 \%$, respectively, and those of the Fe-45 wt\% Gd intermetallics were $741 \pm 13 \mathrm{Hv}, 772 \mathrm{MPa}, 823 \mathrm{MPa}$ and $3 \%$. Passivity was not present in artificial sea water at room temperature. The corrosion potentials and the corrosion rates of the $\mathrm{Fe}-20 \mathrm{wt} \% \mathrm{Gd}$ and $\mathrm{Fe}-45 \mathrm{wt} \%$ Gd intermetallics were $-624 \mathrm{mV}_{\mathrm{SHE}}, 2.771 \mathrm{~mA} / \mathrm{cm}^{2}$, and $-804 \mathrm{mV}_{\mathrm{SHE}}, 3.397 \mathrm{~mA} / \mathrm{cm}^{2}$, respectively. The corroded surface of the $\mathrm{Fe}$-Gd intermetallics contained corrosion products like gadolinium with iron, which detached to leave a trail of pits.
\end{abstract}

(Received April 11, 2016; Accepted August 29, 2016)

Keywords: gadolinium, gd intermetallics, rietveld refinement, mechanical properties, corrosion behaviors.

\section{1. 서 론}

국내 가압경수로(PWR, pressurized water reactor)의 사용 후 핵연료(spent nuclear fuel)는 원전 내의 사용후 핵연료 저 장조에 습식 저장되어 있으며 중수로(CANDU, canada deuterium uranium reactor)의 사용후 핵연료(spent nuclear fuel)는 습식 및 건식 저장 방법을 함께 사용하고 있다 [1]. 국 내 사용후 핵연료는 2013년 12월말 기준으로 원자력발전소 단지 내에 약 18,629 톤이 발생하였고 매년 약 759 톤씩의 사용 후 핵연료가 발생하기 때문에 가압경수로의 경우에는 2016년 부터 고리원전을 시작으로 습식저장시설이 포화되며 중수로 의 경우에는 2022년부터 월성원전이 포화될 것으로 전망된다

*Corresponding Author: Yong Choi [Tel: +82-41-550-3537, E-mail: yochoi@dankook.ac.kr] Copyright (c) The Korean Institute of Metals and Materials
[2]. 포화된 사용 후 핵연료는 필히 원전 부지 내부 시설이나 혹은 사용후 핵연료 저장 시설로 이송 및 저장되어야 한다. 이 와 같은 사용후 핵연료의 처리 문제를 고려하면 핵심 구조용 소재인 중성자 차폐 및 흡수용 합금의 국내 시장 수요가 단기 적으로 급증할 것으로 예상된다 [3]. 또한, 전 세계적으로 원 자력 발전에 대한 전력 의존도가 증가하고 있기 때문에 사용 후 핵연료 운송 및 저장 시설과 관련된 소재와 군사용 고준위 방사선 처리용 소재까지 고려하면 고효율 중성자 흡수 및 차 폐용 소재 개발은 시급히 연구 개발될 필요가 있다 [4].

현재 개발되어 있는 중성자 차폐 및 흡수용 소재는 붕소 (B)와 붕소화합물을 폴리에틸렌과 같은 유기물의 고분자 복 합재료, 붕소-알루미늄 합금, 붕소-스테인레스 강과 가돌리 늄 $(\mathrm{Gd})$-니켈 합금이 있다 [5]. 붕소-고분자 복합재료와 붕소알루미늄 합금 소재는 경량이지만 융점과 기계적 특성을 고 려할 때 고강도 내식성을 요구하는 사용후 핵연료의 이송 및 
저장 용기에 적용하기에는 문제점이 있다. 특히 중성자 흡수 재로 붕소(B)를 사용할 경우에는 붕소가 중성자 조사에 의하 여 핵분열하여 헬륨 $(\mathrm{He})$ 기체를 생성하게 되기 때문에 구조 재의 기계적 특성을 해치므로 사용후 핵연료의 장기 저장 용 기에서는 적용할 수 없는 문제점이 보고되어 있다. 최근 들어 붕소를 대체하는 가돌리늄 $(\mathrm{Gd})$ 을 활용한 중성자 차폐 및 흡 수 소재에 대한 연구가 원전 기술의 선진국에서는 현재 활발 히 진행되고 있으나 소재의 사용 목적상 관련 자료가 많이 공 개되어 있지 않은 실정이다 [6]. 금속학적 관점에서 보면 가 돌리늄의 산소 친화력이 매우 높기 때문에 용해 주조공정에 서 도가니 반응 억제와 초기 장입 함금 조성을 유지에 어려움 이 예상된다 [7]. 이와 같은 문제점을 해결하기 위하여 소량 의 가돌리늄을 함유한 합금을 용해 주조하기 위한 2원계 $\mathrm{Fe}-\mathrm{Gd}$ 모합금을 만들고 합금원소와 재용해하는 공정이 필요 하다. 따라서 본 연구의 목적은 가돌리늄이 소량 첨가된 사용 후 핵연료 운송 및 저장용 첨단 합금을 개발하고 상용화하기 위하여, $\mathrm{Fe}-\mathrm{Gd}$ 합금을 진공 용해하고 주조 조직의 금속학적 특성과 기계적 성질 및 내식성을 평가함으로써 가돌리늄이 소량 첨가된 신합금을 용해 주조하여 제조하기 위한 기초 자 료를 확보하는 데에 있다.

\section{2. 실험 방법}

\subsection{Fe-Gd 주조 금속간 화합물 미세조직 및 상분석}

$\mathrm{Fe}-\mathrm{Gd}$ 모합금의 금속학적 미세조직 평가를 위하여 금속 가돌리늄 $(\mathrm{Gd}, 99.5 \%$, HBVAM, China)과 금속 철( $\mathrm{Fe}, 99.8 \%$, HBVAM, China)을 사용하여 각각 초기 장입 조성이 $\mathrm{Fe}-20$ $\mathrm{wt} \% \mathrm{Gd}, \mathrm{Fe}-45 \mathrm{wt} \% \mathrm{Gd}$ 의 금속간 화합물을 진공 용해 (PAM-Plasma, Japan)하고 $100 \times 120 \times 200$ [mm] 크기의 Y-형 주형에 주조하였다.

미세조직 관찰용 시료는 주조재를 탕구 방향으로 $20 \times 20 \times 5$ $[\mathrm{mm}]$ 로 방전 가공한 시편을 아크릴 수지를 사용하여 마운팅 한 후 \#220-\#2,000 규격의 탄화규소 연마포를 이용하여 연삭 후 $0.5 \mu \mathrm{m}$ 알루미나 연마제를 사용하여 최종 연마하였다. 시 료는 Nital 용액 $\left.\left(\mathrm{HNO}_{3}: \mathrm{C}_{2} \mathrm{H}_{5} \mathrm{OH}\right)=1: 25 \mathrm{vol} \%\right)$ 을 사용하여 30 초 에칭하였다. 에칭된 시편은 $\mathrm{Au}$ 로 진공 증착한 후에 주 사 전자 현미경 (Coxem, CX-200TA, Korea)으로 미세조직을 관찰하였다.

$\mathrm{Fe}-\mathrm{Gd}$ 금속간 화합물의 원소 분석은 에너지 분산 분광기 (energy dispersive spectroscopy, EDS, Oxford, UK)로 분석하 였다. 상분석은 X-선 회절기 (Rigaku, Japan)와 Fullprof (ver.
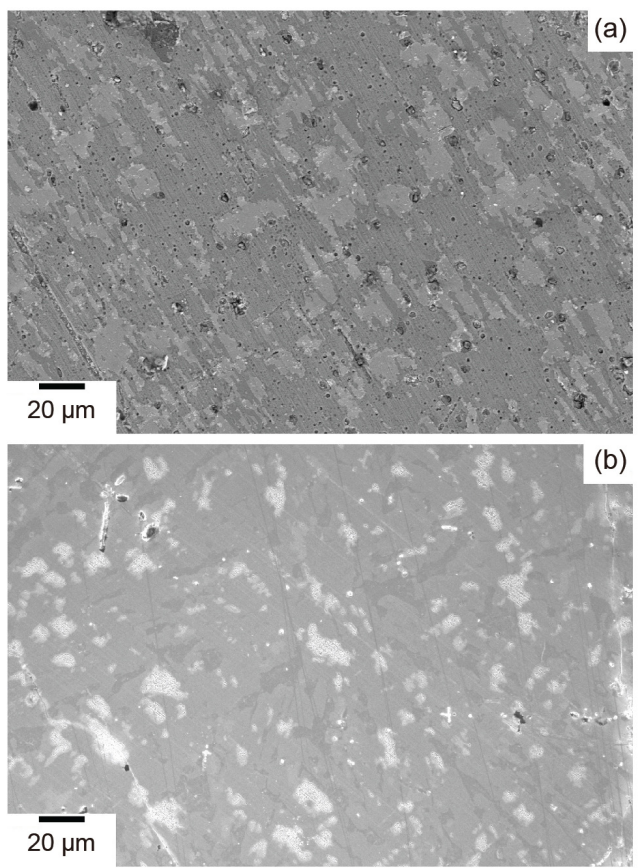

Fig. 1. Microstructure of cast $\mathrm{Fe}-\mathrm{Gd}$ intermetallics with $\mathrm{Gd}$ content : (a) $20 \mathrm{wt} \% \mathrm{Gd}$ (b) $45 \mathrm{wt} \% \mathrm{Gd}$

-2015, ILL, France)을 이용하여 정량 분석하였다. X-선 회절 시험은 $\mathrm{Co} \cdot \mathrm{K}_{\alpha}$ 선을 사용하여 회절각 $5-100^{\circ}$ 까지 $0.0021 \% \mathrm{sec}$ 속도로 상온에서 수행하였다.

\subsection{Fe-Gd 주조 금속간 화합물의 기계적 특성 및 내식성 평가}

$\mathrm{Fe}-\mathrm{Gd}$ 금속간 화합물의 주조재(casting materials)의 기계 적인 기초물성을 평가하기 위하여 경도 시험 (ASTM E-92-82)을 수행하였다. 경도는 주조재를 탕구 방향으로 $20 \times 20 \times 5[\mathrm{~mm}]$ 로 방전 가공한 시편을 마이크로 비커스 경도 기 (HUATEC, HV-1000, China)를 이용하여 $9.8 \mathrm{~N}$ 의 하중 하 에서 총 30 회 측정하여 평균값을 구하였다. 기계적 특성을 금 속간화합물의 주조재의 특성을 고려하여 만능시험기 (Instron 1011, USA)를 사용하여 압축시험(ASTM E-9-09)으 로 수행하였다.

합금의 내식성 평가는 핵연료 운송 및 저장용 케스크 소재 의 국내 사용 지역 조건을 고려하여 상온, 용존산소 분위기의 인공해수(ASTM D1141-98)에서 동적 전기화학적 방법 (Gamry 100, USA)으로 수행하였다. 기준전극과 측정전극은 각각 SCE (saturated calomel electrode)와 백금 전극을 사용 하였으며 SHE (standard hydrogen electrode) 값으로 보정하 여 분석하였다. 


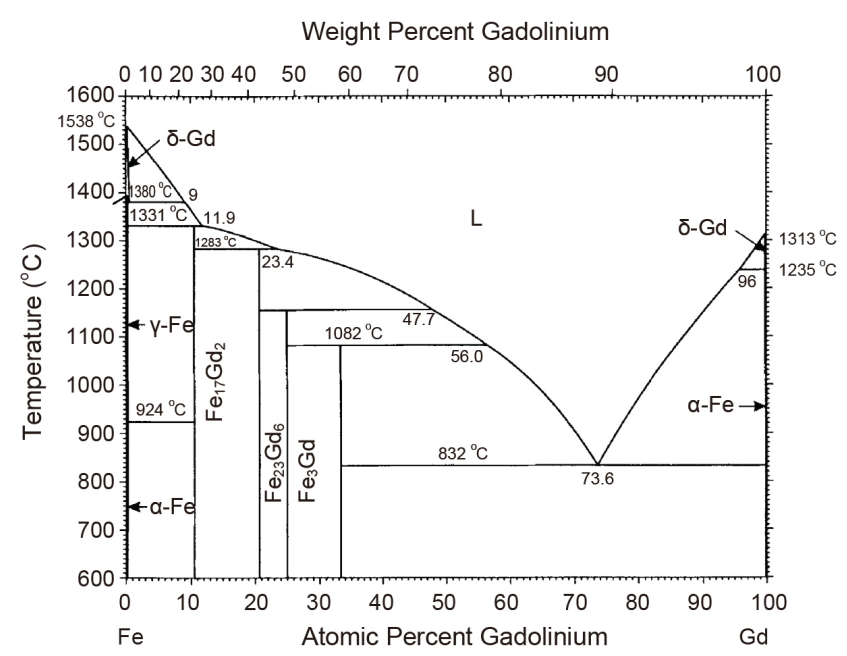

Fig. 2. Binary phase diagram of Fe-Gd Alloys [8]

\section{3. 결과 및 고찰}

\subsection{Fe-Gd 주조 금속간 화합물 미세조직 및 상분석}

그림 1 은 주사 전자 현미경으로 관찰한 $\mathrm{Gd}$ 함량에 따른 $\mathrm{Fe}-\mathrm{Gd}$ 금속간화합물(intermetallic compound)의 탕구 방향으 로의 미세조직이다. 그림 1 에서와 같이 전형적인 주조 조직 인 수지상 조직(dendrite structure)과 주조 기공(cast pore)이 관찰되었다. 이와 같은 수지상정의 크기 변화에 미치는 현상 은 냉각 중에 진행되는 수지상정의 핵 생성과 성장 거동에 의 존한다. 핵생성과 성장 현상은 주어진 온도에서의 용질의 확 산속도, 용해도 및 상태도의 조성/온도기울기 $(\mathrm{dX} / \mathrm{dT})$ 와 관 계있는 액상/고상 계면 이동 현상으로 설명되고 있다. 한편, 주조현장에서 정확한 냉각 속도를 측정하기는 어려우나, 일 반적으로 평형상태도에서 관찰되는 냉각속도보다 빠르고 특 히, $\mathrm{Gd}$ 는 산화성이 매우 높아서 대기와 도가니 반응에 의한 회수율이 낮아서 주조재의 조성이 초기 장입된 조성과는 다 른 것으로 보고되어 있다 [7]. 본 연구에서는 $\mathrm{Fe}-(20,45) \mathrm{wt} \%$ $\mathrm{Gd} 2$ 개의 조성에 대하여 동일한 크기의 Y-형 주형과 용탕 주 입 조건이 유사하기 때문에 두 조성의 주조조직에 차이를 보 여주는 주요 변수는 조성과 상태도의 조성/온도 기울기이다. 그림 2는 $\mathrm{Fe}-\mathrm{Gd}$ 이원계 평형상태도이다 [8]. 그림 2의 $\mathrm{Fe}-\mathrm{Gd}$ 2 원계 상태도에는 공정반응과 다양한 금속간화합물이 생성 된다. $\mathrm{Fe}$ 에 낮은 $\mathrm{Gd}$ 의 용해도를 고려하면 응고 중에는 대부 분의 가돌리늄 $(\mathrm{Gd})$ 은 금속간화합물을 형성하게 된다. 그림 1 의 주사전자 현미경의 후방 산란 전자 영상(backscattered electron image)에서 $\mathrm{Gd}$ 가 $\mathrm{Fe}$ 에 비하여 원자번호가 크기 때
Table 1. Rietveld refinements of the XRD spectra of cast Fe-Gd intermetallics

\begin{tabular}{c|c|c|c|c}
\hline & $\mathrm{Fe}_{2} \mathrm{Gd}$ & $\mathrm{Fe}_{3} \mathrm{Gd}$ & $\mathrm{Fe}_{9} \mathrm{Gd}$ & $\mathrm{Fe}_{17} \mathrm{Gd}_{2}$ \\
\hline $\mathrm{Fe}-20 \mathrm{wt} \% \mathrm{Gd}$ & 26.6 & 73.4 & - & - \\
\hline $\mathrm{Fe}-45 \mathrm{wt} \% \mathrm{Gd}$ & 13.9 & 74.9 & 7.3 & 3.9 \\
\hline
\end{tabular}
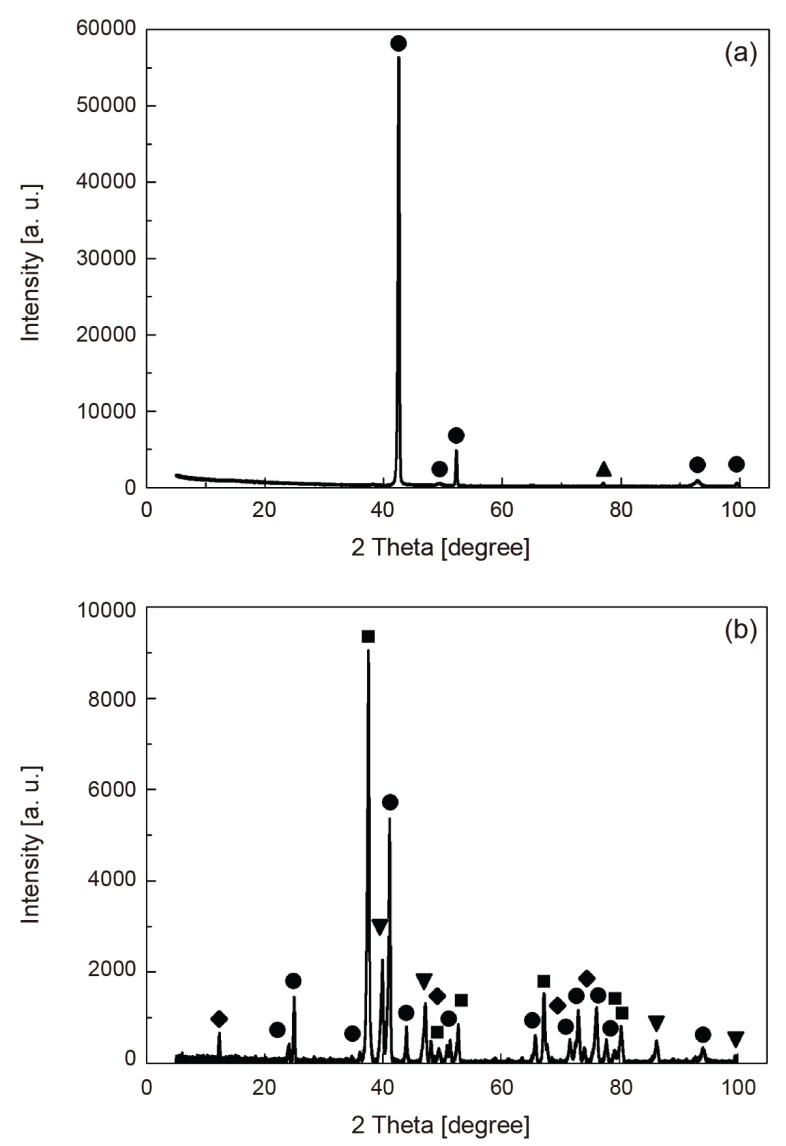

Fig. 3. X-ray spectra of cast Fe-Gd intermetallics with Gd content : (a) $20 \mathrm{wt} \% \mathrm{Gd}$ (b) $45 \mathrm{wt} \% \mathrm{Gd}: \boldsymbol{\nabla}=\mathrm{Fe}_{2} \mathrm{Gd} \boldsymbol{\boldsymbol { }}=\mathrm{Fe}_{3} \mathrm{Gd} \boldsymbol{\Delta}=\mathrm{Fe}_{5} \mathrm{Gd}$ $\bullet=\mathrm{Fe}_{9} \mathrm{Gd}>=\mathrm{Fe}_{17} \mathrm{Gd}_{2}$

문에 밝은 부분이 상대적으로 $\mathrm{Gd}$ 조성이 많은 상이므로 융점 이 낮은 가돌리늄이 많이 존재하는 (Gd-rich) 금속간 화합물 이 나중에 응고된다. $\mathrm{Gd}$-조성이 낮은 곳을 초기 수지상으로 고려하면 수지상정의 단폭(short width)은 초기 장입 조성이 $\mathrm{Fe}-20 \mathrm{wt} \% \mathrm{Gd}$ 주조재에서 약 $2 \mu \mathrm{m}$ 로 짧게 관찰되었고 $\mathrm{Fe}-45 \mathrm{wt} \% \mathrm{Gd}$ 주조재에서는 약 $8 \mu \mathrm{m}$ 로 조대하게 되었으며 상대적으로 Gd-rich 금속간 화합물의 크기는 약 $20 \mu \mathrm{m}$ 이내 크기이다. 따라서 용탕 중에 $\mathrm{Gd}$ 량이 증가하면 융점이 낮은 다양한 금속간 화합물이 생성될 수 있으며 또한 $\mathrm{Gd}$ 함량이 높으면 조대한 수지상이 존재함을 관찰하였다.

$\mathrm{Fe}-\mathrm{Gd}$ 모합금의 조성별 성분 및 상분석을 위하여 X-선 회 

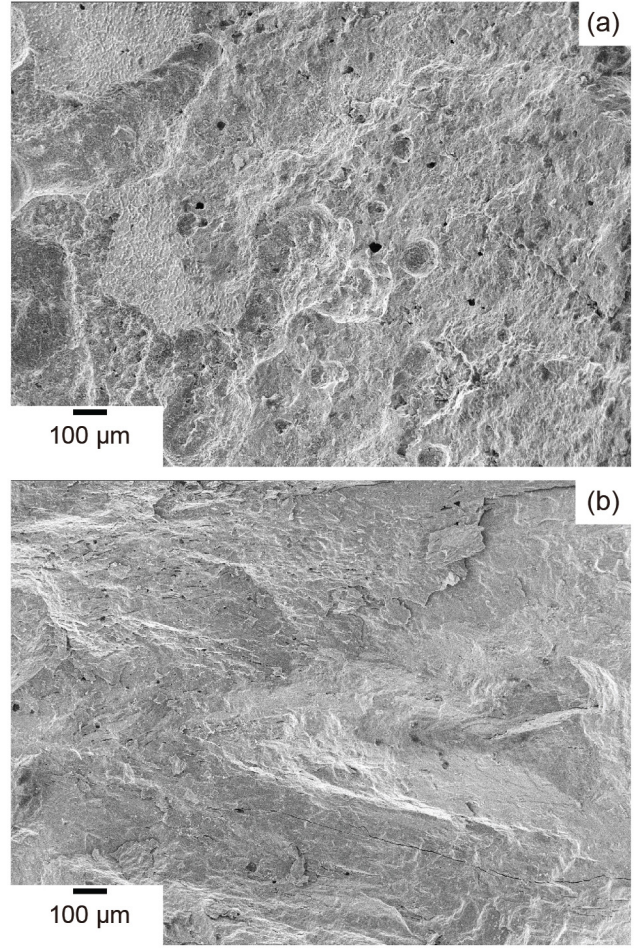

Fig. 4. SEM images of failed cast Fe-Gd intermetallics : (a) 20 wt $\%$ Gd (b) 45 wt $\%$ Gd

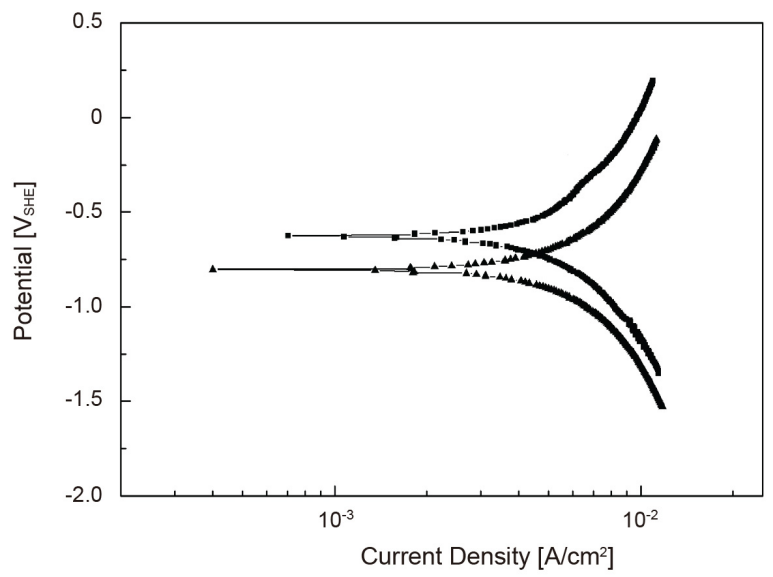

Fig. 5. Polarization curves of cast Fe-Gd intermetallics with $\mathrm{Gd}$ content in artificial sea water : $\boldsymbol{\varpi}=20 \mathrm{wt} \% \mathrm{Gd} \boldsymbol{\Delta}=45 \mathrm{wt} \% \mathrm{Gd}$

절 도형에 대하여 Rietveld 분석을 수행하였다 [9]. Fe-Gd 2원 계 상태도와 JCPDS (the Joint Committee on Powder Diffraction Standards)자료를 고려하면, $\mathrm{Fe}_{2} \mathrm{Gd}(F d 3 m)$,

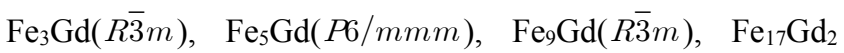
$(P 63 / m m c)$ 와 같은 다양한 금속간화합물이 존재한다. 그림 2 는 $\mathrm{Gd}$ 초기 조성이 다른 $\mathrm{Fe}-\mathrm{Gd}$ 모합금의 X-선 회절도이다.
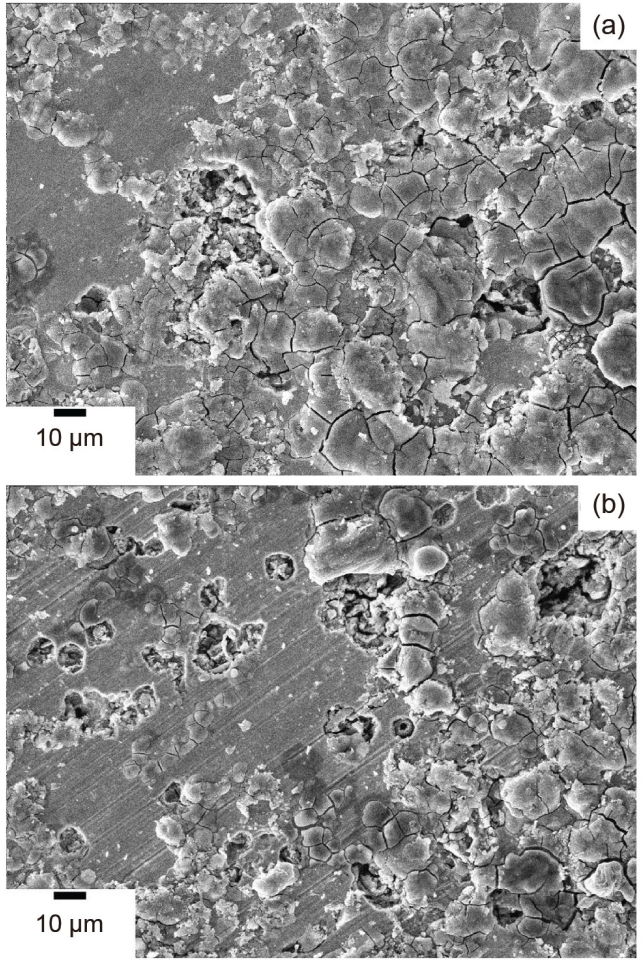

Fig. 6. SEM images of the surfaces of Fe-Gd intermetallics after corrosion test in artificial sea water : (a) $20 \mathrm{wt} \%$ Gd (b) $45 \mathrm{wt} \%$ $\mathrm{Gd}$

표 1은 $\mathrm{Fe}-\mathrm{Gd}$ 조성별 합금의 Rietveld 상분석 결과이다. 표 1 에서와 같이 초기 장입조성이 $\mathrm{Fe}-20 \mathrm{wt} \% \mathrm{Gd}$ 합금은 26.6 $\mathrm{at} \% \mathrm{Fe}_{2} \mathrm{Gd}$ 와 $73.4 \mathrm{at} \% \mathrm{Fe}_{3} \mathrm{Gd}$ 이며 $\mathrm{Fe}-45 \mathrm{wt} \% \mathrm{Gd}$ 합금에는 13.9 at $\% \mathrm{Fe}_{2} \mathrm{Gd}$ 와 74.9 at $\% \mathrm{Fe}_{3} \mathrm{Gd}, 7.3$ at $\% \mathrm{Fe}_{9} \mathrm{Gd}, 3.9$ at $\%$ $\mathrm{Fe}_{17} \mathrm{Gd}_{2}$ 이었다.

\section{2. $\mathrm{Fe}-\mathrm{Gd}$ 주조 금속간 화합물 기계적 특성 및 내식성 평가}

$\mathrm{Fe}-20 \mathrm{wt} \% \mathrm{Gd}$ 와 $\mathrm{Fe}-45 \mathrm{wt} \% \mathrm{Gd}$ 주조된 금속간 화합물의 미세 경도, 압축 항복 강도, 최대 압축 강도 및 연신율은 각각 $629 \pm 12 \mathrm{Hv}, 753 \mathrm{MPa}, 785 \mathrm{MPa}, 4 \%$ 와 $741 \pm 13, \mathrm{Hv}, 772$ $\mathrm{MPa}, 823 \mathrm{MPa}, 3 \%$ 이었다. 그림 4는 파단면을 주사 전자 현 미경으로 관찰한 사진이다. 그림 4에서와 같이 Fe-Gd 금속간 화합물의 파단면은 벽계 파면 양식을 보여주고 있다. 이는 경 도값에 비하여 낮은 압축강도와 낮은 연신율은 금속간 화합 물의 취성과 주조 기공과 관련이 있는 것으로 사료된다.

그림 5 는 $\mathrm{Fe}-\mathrm{Gd}$ 주조 금속간 화합물의 $\mathrm{Gd}$ 함량에 따른 인 공해수(ASTM D1141-98) 분위기에서의 분극곡선(polarization curve)이다. 그림 3-5에서와 같이 인공해수 분위기에서 부동 

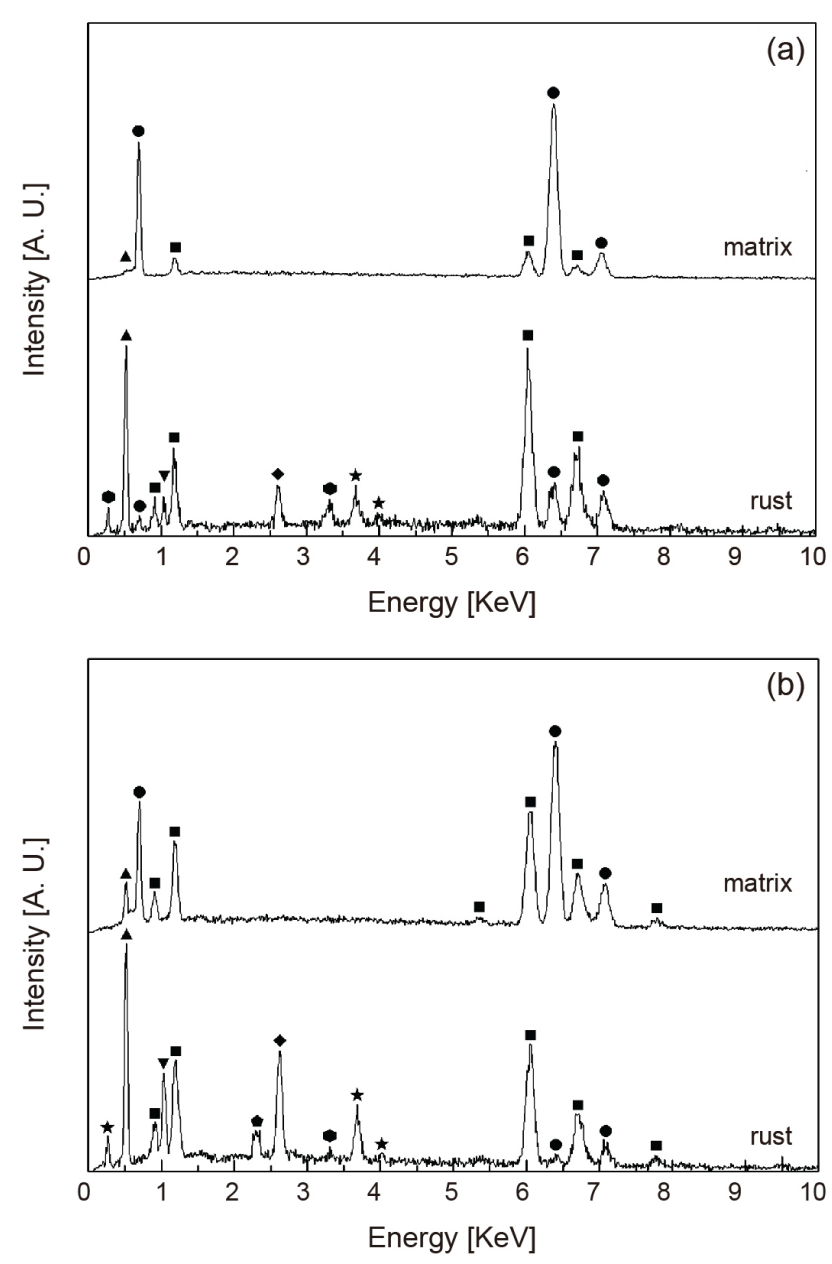

Fig. 7. Chemical composition of as-received and corroded cast Fe-Gd intermetallics by XRF : (a) $20 \mathrm{wt} \% \mathrm{Gd}$ (b) $45 \mathrm{wt} \% \mathrm{Gd}$ (匹 $=\mathrm{Gd} \bullet=\mathrm{Fe} \boldsymbol{\Delta}=\mathrm{O} \boldsymbol{\nabla}=\mathrm{Na} \boldsymbol{\nabla}=\mathrm{Cl} \star=\mathrm{Ca} \boldsymbol{\bullet}=\mathrm{S} \boldsymbol{\boldsymbol { N }})$

태는 관찰되지 않았다. $\mathrm{Fe}-\mathrm{Gd}$ 주조 합금의 $\mathrm{Gd}$ 함량에 인공해 수 분위기에서의 부식 전위와 부식 속도는 -624 -804 $\left[\mathrm{mV}_{\mathrm{SHE}}\right], 2.771 \sim 3.397\left[\mathrm{~mA} / \mathrm{cm}^{2}\right]$ 으로, $\mathrm{Gd}$ 양이 증가하면 부식전위는 감소하였고 부식속도는 증가하였다. 특히 인공 해수 $(\mathrm{pH}=6)$ 에서는 산도가 중성임에도 불구하고 내식성이 낮 음을 알 수 있었다.

그림 6은 주사 전자 현미경으로 $\mathrm{Fe}-\mathrm{Gd}$ 주조 합금의 부식된 표면이다. 그림 6에서와 같이 가돌리늄 $(\mathrm{Gd})$ 함량이 $20 \mathrm{wt} \%$ 에 서 $45 \mathrm{wt} \%$ 로 증가하면 약 $10 \mu \mathrm{m}$ 크기의 공침(pits)이 관찰되 었다. 공침의 크기는 그림 1 의 미세조직에서와 같이 가돌리늄 $(\mathrm{Gd})$ 이 많은 상의 크기와 유사한 크기였다. 이는 가돌리늄이 많은 구역이 상대적으로 내식성이 낮음을 의미한다. 이를 확 인하고자 모재와 부식생성물의 원소분석을 수행하였다.

그림 7은 X-선형광분석기 (X-ray Fluorescence, XRF)를 이
Table 2. XRF results of as-received and corroded surfaces of cast Fe-Gd intermetallics [wt $\%$ ]

\begin{tabular}{c|c|c|c|c|c|c|c|c|c}
\hline specimen & area & $\mathrm{Fe}$ & $\mathrm{Gd}$ & $\mathrm{Ca}$ & $\mathrm{K}$ & $\mathrm{Na}$ & $\mathrm{Cl}$ & $\mathrm{O}$ & $\mathrm{Gd} / \mathrm{Fe}$ \\
\hline $\mathrm{Fe}-20$ & $\begin{array}{c}\text { matrix } \\
\text { surface }\end{array}$ & 73.88 & 24.69 & - & - & - & - & 1.43 & 0.33 \\
\cline { 2 - 9 } $\mathrm{wt} \% \mathrm{Gd}$ & $\begin{array}{c}\text { corrosion } \\
\text { surface }\end{array}$ & 8.62 & 70.93 & 1.77 & 1.29 & 1.29 & 2.23 & 13.87 & 8.22 \\
\hline $\mathrm{Fe}-45$ & $\begin{array}{c}\text { matrix } \\
\text { surface }\end{array}$ & 50.72 & 47.65 & - & - & - & - & 1.63 & 0.10 \\
\cline { 2 - 9 } $\mathrm{wt} \% \mathrm{Gd}$ & $\begin{array}{c}\text { corrosion } \\
\text { surface }\end{array}$ & 1.81 & 59.49 & 3.44 & 0.52 & 3.74 & 7.66 & 22.94 & 32.9 \\
\hline
\end{tabular}

용한 모재와 인공해수에 침지 후 부식된 표면과 원소분석결 과이다. 그림 7에서와 같이 모재(matrix)는 철( $\mathrm{Fe}$ )과 가돌리 늄(Gd)으로 구성되어 있으며 부식생성물(rust)은 모재의 조 성인 철 $(\mathrm{Fe})$ 과 가돌리늄 $(\mathrm{Gd})$ 이외에도 인공해수의 성분인 칼 슘 $(\mathrm{Ca})$, 나트륨 $(\mathrm{Na})$, 칼륨 $(\mathrm{K})$, 염소 $(\mathrm{Cl})$ 와 같은 다양한 원소가 관찰되었다. 표 2는 XRF로 분석한 $\mathrm{Fe}-\mathrm{Gd}$ 금속간 화합물의 모재와 인공해수 분위기에서의 부식 생성물의 원소분석 결 과이다. $\mathrm{Fe}-20 \mathrm{wt} \% \mathrm{Gd}$ 금속간 화합물은 $26.6 \mathrm{at} \% \mathrm{Fe}_{2} \mathrm{Gd}$ 와 $73.4 \mathrm{at} \% \mathrm{Fe}_{3} \mathrm{Gd}$ 로 구성되어 있는데 $\mathrm{XRF}$ 분석에서 $\mathrm{Gd} / \mathrm{Fe}$ 는 0.34 이었다. 화합물의 상에 따른 XRF 방출 오차를 고려하면 초기 조성과 유사하다. 부식 생성물의 $\mathrm{Gd} / \mathrm{Fe}$ 는 8.22 로 매우 크다. 한편 $\mathrm{Fe}-45 \mathrm{wt} \% \mathrm{Gd}$ 금속간 화합물은 $13.9 \mathrm{at} \% \mathrm{Fe}_{2} \mathrm{Gd}$, 74.9 at $\% \mathrm{Fe}_{3} \mathrm{Gd}, 7.3 \mathrm{at} \% \mathrm{Fe} \mathrm{Gd} \mathrm{G}, 3.9 \mathrm{at} \% \mathrm{Fe}_{17} \mathrm{Gd}_{2}$ 구성되어 있 고 XRF 분석에서는 모재의 $\mathrm{Fe} / \mathrm{Gd}$ 는 1.0 으로 초기 조성과 유 사하다. 부식 생성물은 $\mathrm{Gd} / \mathrm{Fe}$ 가 32.9 로 매우 크다. 부식생성 물에는 산소의 함량이 $22.94 \mathrm{wt} \%$ 로 높게 관찰되었기 때문에 $\mathrm{Fe}-\mathrm{Gd}$ 금속간화합물의 부식된 표면에는 다량의 $\mathrm{Gd}$-산화물 과 일부 $\mathrm{Fe}$-산화물이 존재함을 의미한다.

이와 같이 부식 생성물에 $\mathrm{Gd}$ 이 다량 존재하는 이유는 용 액중의 상의 열역학적 안정성을 고려하여 설명될 수 있다. 상 온에서 $\mathrm{Gd}_{2} \mathrm{O}_{3}, \mathrm{Gd}(\mathrm{OH})_{3}, \mathrm{Gd}^{+3}$ 의 Gibb's 자유에너지 변화는 각각 -98.36, -77.7, -37.8 [KJ/mole] 이며, $\mathrm{Fe}_{2} \mathrm{O}_{3}, \mathrm{Fe}_{3} \mathrm{O}_{4}$, $\mathrm{Fe}(\mathrm{OH})_{2}, \mathrm{Fe}(\mathrm{OH})_{3}, \mathrm{Fe}^{+2}$ 의 경우 각각 -42.2, -57.8, -27.7, -39.6 $[\mathrm{KJ} / \mathrm{mole}]$ 이다 [10]. 이는 산화 가돌리늄이나 수산화 가돌리 늄이 산화철이나 수산화철보다 열역학적으로 안정한 상이 며, 가돌리늄이 철보다 우선적으로 이온화되어 안정한 부식 생성물로 진행되는 것을 의미한다. 한편 부식생성물에 철이 온이 비교적 적게 관찰된 이유는 낮은 전위 구역에서는 가돌 리늄이 선택적으로 부식이 진행되어 철의 양극 부식이 적게 진행되었거나, 또한 철의 부식기구(corrosion mechanism)를 고려하면 $\mathrm{FeOCl}$ 과 같은 수용성 부식 생성물을 형성하게 되 

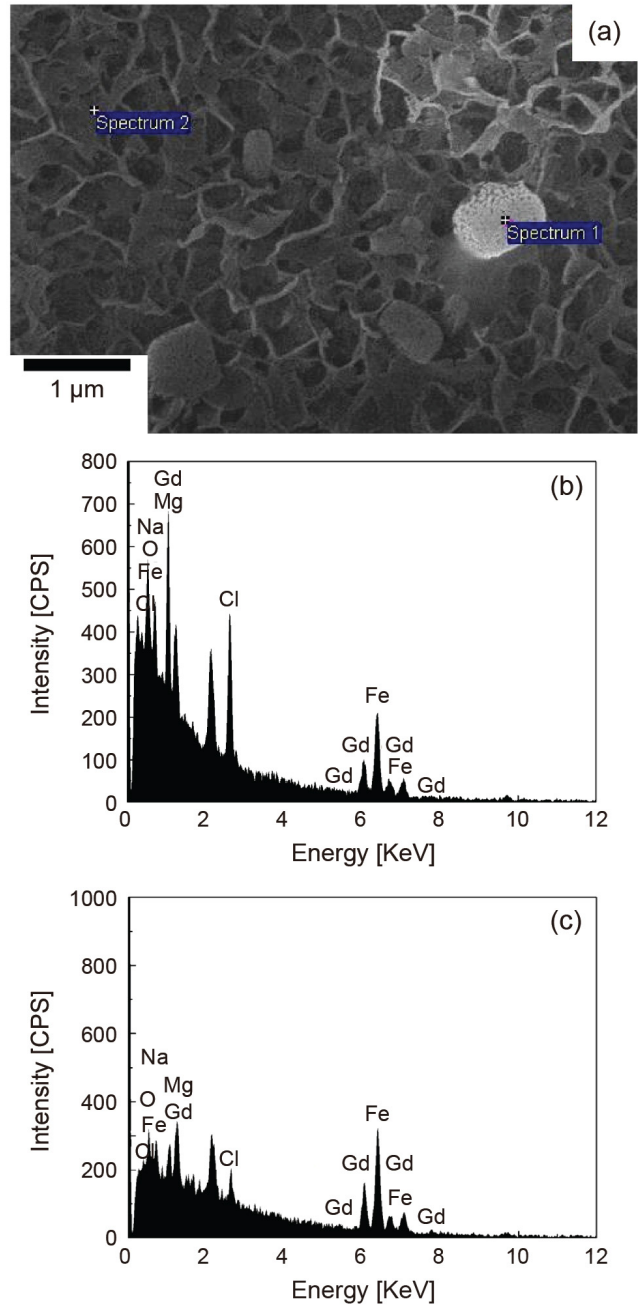

Fig. 8. Typical SEM image and chemical composition of corrosion products of cast $\mathrm{Fe}-20 \% \mathrm{Gd}$ intermetallics in artificial sea water by EDS : (a) SEM (b) EDS-spectrum 1 (c) EDS-spectrum 2

어 부식생성물에는 양극 용해된 양보다 적게 측정될 수 있다 [11-13]. 이는 인공해수 분위기에서 $\mathrm{Fe}-\mathrm{Gd}$ 금속간 화합물의 부식 생성물의 $\mathrm{Gd} / \mathrm{Fe}$ 의 높은 비율은 가돌리늄이 철과 비교 하여 선택적 부식이 우선적으로 진행되는 것을 알 수 있었다.

부식 생성물의 조성은 산소와 수산화기의 조성에 크게 의 존한다. 방출부피 (emission volume)을 고려하면 XRF의 분 석보다는 전자선에 의한 분석이 표면에 직하의 원소분석이 가능하다 [14-17]. 본 연구에서는 부식생성물에 철의 성분이 상대적으로 적은 이유를 연구하고자 부식에 의하여 탈착된 생성물의 표면의 성분을 전자분산분광기(EDS)로서 원소 분 석을 수행하였다. 그림 8과 그림 9는 부식된 표면과 탈착된 부식생성물을 주사전자현미경 관찰과 $\mathrm{EDS}$ 원소 분석한 결 과이며 표 3에 정리하였다. $\mathrm{Fe}-20 \mathrm{wt} \% \mathrm{Gd}$ 금속간 화합물의
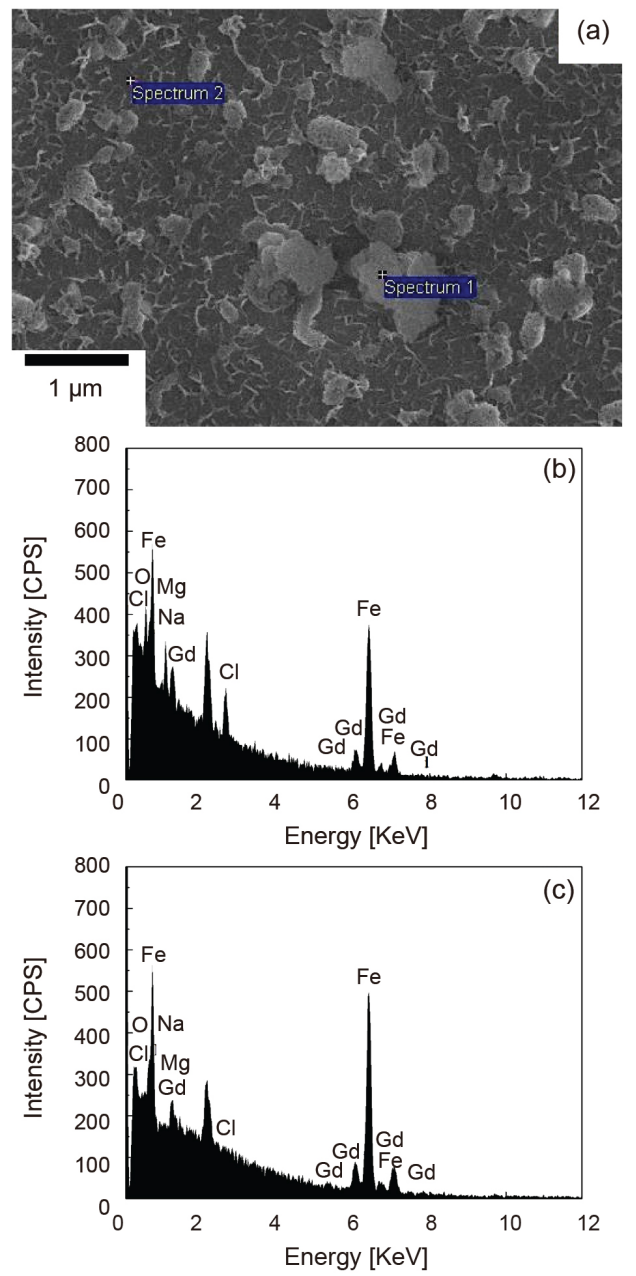

Fig. 9. Typical SEM image and chemical composition of corrosion products of cast $\mathrm{Fe}-45 \% \mathrm{Gd}$ intermetallics in artificial sea water by EDS : (a) SEM (b) EDS-spectrum 1 (c) EDS-spectrum 2

Table 3. EDX results of cast Fe-Gd intermetallics and corrosion products formed in artificial sea water [ $\mathrm{wt} \%]$

\begin{tabular}{c|c|c|c|c|c|c|c|c}
\hline specimen & position & $\mathrm{Fe}$ & $\mathrm{Gd}$ & $\mathrm{Na}$ & $\mathrm{Mg}$ & $\mathrm{Cl}$ & $\mathrm{O}$ & $\mathrm{Gd} / \mathrm{Fe}$ \\
\hline \multirow{2}{*}{$\begin{array}{c}\mathrm{Fe}-20 \\
\mathrm{wt} \% \mathrm{Gd}\end{array}$} & $\begin{array}{c}\text { matrix } \\
\text { corrosion } \\
\text { surface }\end{array}$ & 89.25 & 10.75 & - & - & - & - & 0.12 \\
\cline { 2 - 9 } & $\begin{array}{c}\text { corrosion } \\
\text { debris }\end{array}$ & 14.69 & 4.72 & 22.25 & 7.91 & 10.42 & 40.01 & 0.32 \\
\hline \multirow{2}{*}{$\begin{array}{c}\mathrm{Fe}-45 \\
\mathrm{wt} \% \mathrm{Gd}\end{array}$} & $\begin{array}{c}\text { matrix } \\
\text { corrosion } \\
\text { surface }\end{array}$ & 75.16 & 24.84 & - & - & - & - & 0.33 \\
\hline $\begin{array}{c}\text { corrosion } \\
\text { debris }\end{array}$ & 39.60 & 8.07 & 3.31 & 2.80 & 0.53 & 7.28 & 0.10 \\
\hline
\end{tabular}

모재는 표 2의 XRF에서 분석한 결과와 표 3 의 $\mathrm{EDS}$ 결과와 비교하면 모재의 성분비는 오차범위에서 일치하였다. Fe-20 
$\mathrm{wt} \% \mathrm{Gd}$ 금속간 화합물의 경우 모재의 $\mathrm{Gd} / \mathrm{Fe}$ 는 0.12 이며 부 식된 표면과 표면의 부식생성물의 $\mathrm{Gd} / \mathrm{Fe}$ 는 각각 0.37 과 0.32 유사하고 모재보다 높게 관찰되었다. 이는 $\mathrm{Fe}-20 \mathrm{wt} \% \mathrm{Gd}$ 금 속간화합물에서 가돌리늄이 철보다 빠르게 부식되고 표면에 부식 생성물과 탈착된 부식생성물은 유사한 조성을 가고 있 음을 의미한다. 이는 앞선 XRF 분석 결과와 일치한다. 한편, $\mathrm{Fe}-45 \mathrm{wt} \% \mathrm{Gd}$ 금속간 화합물의 경우 그림 5에서와 같이 부 식전위가 낮고 부식속도가 상대적으로 빠르다. 모재의 $\mathrm{Gd} / \mathrm{Fe}$ 는 0.33 이며 부식된 표면과 표면의 부식생성물 $\mathrm{Gd} / \mathrm{Fe}$ 비율은 각각 0.10 과 0.12 로서 유사하지만 모재보다 $\mathrm{Fe}$ 의 함 량이 높게 관찰되었다. 이는 부식 현상이 낮은 부식 전위에서 가돌리늄이 선택적으로 부식되고 일부 철이 부식되어 부식 생성물을 형성하는데, 탈착된 부식생성물은 철의 성분을 상 대적으로 많은 것은 부식된 생성물 중에서 철의 산화물이 존 재하는 부위가 탈착된 것을 의미한다.

\section{4. 결 론}

1. 주조된 $\mathrm{Fe}-\mathrm{Gd}$ 금속간 화합물의 미세조직은 수지상 조직 (dendrite structure)과 주조 기공(cast pore)이 존재하였다. 초 기 장입된 가돌리늄 $(\mathrm{Gd})$ 함량이 증가하면 탕구 방향으로의 수지상의 단폭(short width)은 조대하게 되었다.

2. 주조된 $\mathrm{Fe}-\mathrm{Gd}$ 금속간 화합물의 조성은 초기 장입조성이 $\mathrm{Fe}-20 \mathrm{wt} \% \mathrm{Gd}$ 이면 $26.6 \mathrm{at} \% \mathrm{Fe}_{2} \mathrm{Gd}(F d 3 m)$ 와 $73.4 \mathrm{at} \%$ $\mathrm{Fe}_{3} \mathrm{Gd}(R \overline{3} m)$ 이며 $\mathrm{Fe}-45 \mathrm{wt} \% \mathrm{Gd}$ 이면 13.9 at $\% \mathrm{Fe}_{2} \mathrm{Gd}$ $(F d 3 m), 74.9$ at $\% \mathrm{Fe}_{3} \mathrm{Gd}(R \overline{3} m), 7.3$ at $\% \mathrm{Fe}_{9} \mathrm{Gd}(P 63 / m m c)$, 3.9 at $\% \mathrm{Fe}_{17} \mathrm{Gd}_{2}(P 63 / \mathrm{mmc})$ 이었다.

3. $\mathrm{Fe}-20 \mathrm{wt} \% \mathrm{Gd}$ 와 $\mathrm{Fe}-45 \mathrm{wt} \% \mathrm{Gd}$ 주조된 금속간 화합물 의 미세경도, 압축항복강도, 최대압축강도 및 연신율은 각각 $629 \pm 12 \mathrm{Hv}, 753 \mathrm{MPa}, 785 \mathrm{MPa}, 4 \%$ 와 $741 \pm 13, \mathrm{Hv}, 772$ $\mathrm{MPa}, 823 \mathrm{MPa}, 3 \%$ 이었다.

4. Fe-Gd 금속간 화합물의 상온 인공해수에서의 부식전위 와 부식 속도는 가돌리늄 $(\mathrm{Gd})$ 함량이 20 에서 $45 \mathrm{wt} \%$ 로 증가 하면 각각 $-624 \mathrm{mV} \mathrm{SHE}_{\text {와 }} 2.771 \mathrm{~mA} / \mathrm{cm}^{2}$ 에서 $-804 \mathrm{mV} \mathrm{SHE}_{\text {와 }}$ $3.397 \mathrm{~mA} / \mathrm{cm}^{2}$ 로 변화하였다. 부식 현상은 가돌리늄이 많은 구역이 선택적으로 부식이 진행되고 표면에 존재하는 부식 생성물은 주로 산화 가돌리늄과 일부 철의 산화물이며, 철의 산화물이 다량 존재하는 부식 생성물은 주로 탈착되는 것으 로 사료된다.

\section{감사의 글}

본 연구는 산업통상자원부(Ministry of Trade, Industry and Energy)가 지원하는 한국에너지기술평가원(KETEP)의 에너 지기술개발사업의 연구과제(No. 20141710201690)로 수행 되어 이에 감사드립니다.

\section{REFERENCES}

1. C. H. Kim, The Korean Academy of Science and Technology, KAST-RR-057 (2009).

2. H. D. Jeong and W. J. Park, Korea Institute of Nuclear Safety, KINS-RR-1255 (2005).

3. J. H. Ko, J. H. Park, I. S. Jung, G. U. Lee, C. Y. Baeg, and T. M. Kim, Nucl. Eng. Technol. 46, 547 (2014).

4. F. Upton and J. Shimkus, GAO-RR-16-141, USA (2014).

5. A. Machiels, R. Lambert, 2009-ed EPRI-RR-1019110, Electronic Power Research Institute, USA (2009).

6. G. W. Wachs, J. W. Sterbentz, L. M. Montierth, F. K. Tovesson, and T. S. Hill, INL/CON-07-12838, Idaho National Laboratory (2007).

7. Y. Choi, Y. Baik, B. M. Moon, and D.-S. Sohn, Nucl. Eng. Technol. 25, 689 (2013).

8. H. Okamoto, Phase Diagrams of Binary Iron Alloys, ASM International, Materials Park, OH, pp. 341-349 (1993).

9. R. A. Young, The Rietveld Method, International Union of Crystallography, Oxford Scientific Press, Oxford, UK, pp. 5-27 (1981).

10. M. W. Chase, NIST-JANF Thermochemical Tables, 4th ed. American Institute of Physics for the National Institute of Standards and Technology, Washington D.C, (1998).

11. J. B. Lumsden and R. W. Staehle, Scripta Metall. Mater. 6, 1205 (1972).

12. Y. S. Kim, S. J. Park, and H. Y. Chang, Met. Mater. Int. 20, 69 (2014).

13. Y. J. Cho, H. C. Yang, H. and C. Eun, E. H. Kim, and I. T. Kim, J. Nucl. Sci. Technol. 43, 1280 (2006).

14. S. T. Kim, I. S. Lee, K. H. Kong, Y. S. Park, J. H. Lee, and W. J. Yan, Korean J. Met. Mater. 53, 464 (2015).

15. U. B. Baek, B. H. Choe, J. H. Lee, J. H. Shim, E. S. Kim, and S. H. Nam, Korean J. Met. Mater. 53, 20 (2015).

16. J. K. Kwon, D. H. Ahn, D. H. Jeong, Y. J. Kim, N. S. Woo, and S. S. Kim, Korean J. Met. Mater. 52, 757 (2014).

17. H. J. Park and H. W. Lee, Korean J. Met. Mater. 52, 211 (2014). 